\title{
Suppression of metastasis of intravenously-inoculated B16/F10 melanoma cells by the novel ginseng-derived ingredient, gintonin: Involvement of autotaxin inhibition
}

\author{
SUNG HEE HWANG ${ }^{1 *}$, BYUNG-HWAN LEE ${ }^{1 *}$, HYEON-JOONG KIM $^{1 *}$, HEE-JUNG CHO ${ }^{2}$, HO-CHUL SHIN ${ }^{2}$, \\ KEUM-SOON IM ${ }^{3}$, SUN-HYE CHOI ${ }^{1}$, TAE-JOON SHIN ${ }^{1}$, SANG-MOK LEE ${ }^{1}$, SUK WOO NAM ${ }^{4}$, \\ HYOUNG-CHUN KIM ${ }^{5}$, HYEWON RHIM ${ }^{6}$ and SEUNG-YEOL NAH ${ }^{1}$

\begin{abstract}
Departments of ${ }^{1}$ Physiology and Bio/Molecular Informatics Center, ${ }^{2}$ Pharmacology and Toxicology and ${ }^{3}$ Pathology, College of Veterinary Medicine, Konkuk University; ${ }^{4}$ Department of Pathology, College of Medicine,

The Catholic University of Korea, Seoul; ${ }^{5}$ Neuropsychopharmacology and Toxicology Program, College of Pharmacy, Kangwon National University, Chunchon; ${ }^{6}$ Life Science Division,

Korea Institute of Science and Technology, Seoul, Republic of Korea
\end{abstract}

Received September 17, 2012; Accepted November 5, 2012

DOI: 10.3892/ijo.2012.1709

\begin{abstract}
Ginseng has been used for cancer prevention. However, little is known about its active components and the molecular mechanisms underlying its effects. Recently, we isolated a unique lysophosphatidic acid (LPA) receptor ligand, gintonin. Gintonin contains approximately 9.5\% LPA, mainly LPA $C_{18: 2}$. Autotaxin (ATX) is responsible for metastasis by overproducing LPA in cancers. However, LPA, particularly LPA $\mathrm{C}_{18: 2}$, is a strong negative feedback ATX inhibitor. It is unknown whether gintonin inhibits ATX activity and whether gintonin-induced ATX inhibition is coupled with antimetastatic activity. In this study, we examined whether gintonin and LPA $\mathrm{C}_{18: 2}$ inhibit ATX activity and metastasis-related cellular activities in melanoma cells. We found that gintonin and LPA $\mathrm{C}_{18: 2}$ inhibited the purified and secreted ATX activity from melanoma cells in a concentration-dependent manner. Gintonin also inhibited cell migration with a minimal inhibition of cell growth. The oral administration of gintonin or LPA $\mathrm{C}_{18: 2}$ inhibited lung metastasis induced by tail-vein inoculations of melanoma cells. Moreover, the oral administration of gintonin significantly suppressed the tumor growth induced by subcutaneous grafts of melanoma cells. A histological analysis showed that the oral administration of gintonin reduced
\end{abstract}

Correspondence to: Professor Seung-Yeol Nah, Department of Physiology and Bio/Molecular Informatics Center, College of Veterinary Medicine, Konkuk University, 1 Hwayang-dong, Gwangjin-gu, Seoul 143-701, Republic of Korea

E-mail: synah@konkuk.ac.kr

*Contributed equally

Key words: Panax ginseng, gintonin, lysophosphatidic acid, autotaxin, metastasis, anti-metastasis, B16/F10 melanoma cells tumor necrosis, the pleomorphism of tumor cells, tumor cell mitosis and angiogenesis. The present study demonstrates that the gintonin-induced inhibition of ATX activity may be the molecular basis of ginseng-induced antimetastatic and antitumor activities.

\section{Introduction}

Lysophosphatidic acid (LPA; acyl-glycerol-3-phosphate) is a phospholipid growth factor that exerts diverse biological effects in cellular and organ systems (1-3). LPA exhibits multiple physiological activities through the activation of LPA receptors $\left(\mathrm{LPA}_{1-6}\right)$, which are G-protein coupled receptors (GPCRs) that act through various downstream signal transduction pathways (4). LPAs are produced from lysophosphatidylcholine by autotaxin (ATX) (also known as lysophospholipase D, lyso PLD) in the blood (5-7).

Of note, in LPA-related cancer pathophysiology, melanoma cell lines secrete ATX and facilitate cell migration. In previous studies, the ATX-LPA axis has been shown to function as a mitogen and motility factor for various types of cancer, including neuroblastoma, hepatoma, lung cancer, ovarian cancer, metastatic breast cancer and melanoma, and these cancers produce high levels of ATX (7). Thus, ATX was first identified as an autocrine tumor cell motility factor (8). However, LPA is a strong negative feedback ATX inhibitor with high affinity (9). Therefore, LPA-related compounds, such as Brp-LPA and cyclic phosphatidic acids, which inhibit ATX activity, have been investigated as putative anticancer or antimetastatic agents (10-12).

Ginseng, a traditional herbal medicine, has been used for cancer prevention $(13,14)$. However, little is known about the active components and molecular mechanisms underlying the effects of ginseng. Recently, we isolated a novel glycolipoprotein from Panax ginseng, gintonin, which was identified as a LPA complex with ginseng proteins (15). Similar to LPA, gintonin activates LPA receptors in cells expressing endog- 
enous and heterologous LPA receptors (16). Gintonin contains approximately $9.5 \%$ LPA and the major LPA of gintonin is LPA $C_{18: 2}$ (16). A previous study demonstrated that LPA $C_{18: 2}$ potently inhibits ATX activity compared to other LPAs (17). However, the effects of gintonin on ATX activity, on metastasis-related cellular effects in vitro and on metastasis and tumor growth in vivo remain unknown.

In the present study, we report that gintonin potently inhibits ATX activity. In addition, gintonin inhibits cellular metastasis-related cell migration. The oral administration of gintonin inhibits lung metastasis and tumor growth in mice. We discuss the mechanisms involved in the gintonin-mediated antimetastatic effects and inhibition of tumor growth. Finally, we propose that gintonin may be useful for targeted metastasis prevention or therapy.

\section{Materials and methods}

Materials. Gintonin was isolated from Panax ginseng as described in our previous study (15). The BrdU incorporation assay ELISA kit was purchased from Roche Diagnostics (Mannheim, Germany). Penicillin, streptomycin, DMEM and FBS were purchased from Life Technologies (Grand Island, NY, USA). ATX Inhibitor Screening kits, FS-3, Brp-LPA and LPA $C_{18: 2}$ were purchased from Echelon Biosciences Inc. (Salt Lake City, UT, USA). Zoletil 50 was purchased from Virbac (Carros, France). Rompun was purchased from Bayer Korea (Seoul, Korea). All other reagents used were purchased from Sigma-Aldrich Co. (St. Louis, MO, USA).

ATX inhibition assay. First, the inhibitory effects of gintonin on ATX activity were examined using ATX Inhibitor Screening kits according to the manufacturer's instructions. The ATXmediated hydrolysis of the fluorogenic ATX substrate, FS-3, produces fluorescein fluorescence by a fluorescence resonance energy transfer (18). Briefly, ATX was incubated with either gintonin or Brp-LPA as a standard inhibitor at different concentrations in a 96-well plate. FS-3 was then added and the resulting fluorescence was measured over time [excitation (Ex), $485 \mathrm{~nm}$; emission (Em), $528 \mathrm{~nm}$ ]. The percent inhibition was calculated from the slopes of the fluorescence versus time graphs of each standard, sample and blank.

Cell culture. The B16/F10 murine melanoma cell line was purchased from the Korean Cell Line Bank (KCLB; Seoul, Korea) (19) and the MDA-MB-435 human melanoma cancer cell line was a kind gift from Professor Woong-Yang Park (College of Medicine, Seoul National University, Seoul, Korea). The cells were cultured in DMEM supplemented with $10 \%$ (v/v) FBS, $100 \mathrm{U} / \mathrm{ml}$ penicillin and $100 \mu \mathrm{g} / \mathrm{ml}$ streptomycin.

Measurement of ATX activity in the conditioned medium from melanoma cells. The conditioned medium containing ATX was collected and concentrated from melanoma cells, as previously described and ATX activity in the medium was measured using fluorogenic ATX substrate FS-3 (20-22). Briefly, the cells were grown in 100-mm cell culture dishes until 60-70\% confluence. The growth medium was removed and washed with serum-free DMEM. The medium was replaced with $10 \mathrm{ml}$ of DMEM containing $0.1 \%$ BSA and subsequently incubated for $48 \mathrm{~h}$ at $37^{\circ} \mathrm{C}$. The conditioned medium was collected and centrifuged at $1,500 \mathrm{x}$ g for $10 \mathrm{~min}$ at $4^{\circ} \mathrm{C}$. The supernatant was collected and concentrated 100-fold using an Amicon Ultra 4 centrifugal filter device (50K) (EMD Millipore, Billerica, MA, USA). The conditioned media were washed with storage buffer (50 mM Tris, 20\% ethylene glycol, pH 7.5) 3 times in the same Centrifugal Filter Device. The concentrated and conditioned medium was diluted in Tris-buffered saline solution (TBS: $140 \mathrm{mM} \mathrm{NaCl}, 5 \mathrm{mM} \mathrm{KCl}, 1 \mathrm{mM} \mathrm{CaCl} 2,1 \mathrm{mM} \mathrm{MgCl}$, $50 \mathrm{mM}$ Tris-HCl, $\mathrm{pH}$ 8.0) and incubated with different concentrations of gintonin or LPA $\mathrm{C}_{18: 2}$ for $10 \mathrm{~min}$ in a 96-well plate. FS-3 in TBS containing $0.1 \%$ charcoal-treated BSA was then added to each well of the 96-well plate (final concentration of FS-3, $2.5 \mu \mathrm{M})$ and the resulting fluorescence was measured for $24 \mathrm{~h}$ (Ex, $485 \mathrm{~nm}$; Em, $528 \mathrm{~nm}$ ). The percentage inhibition was calculated from the slopes of the fluorescence intensity versus the time graphs of each well.

Scratch-wound healing assay. An in vitro migration (scratchwound healing) assay was subsequently performed as described previously (23). Briefly, cells were seeded in 24-well plates $\left(1.5 \times 10^{5}\right.$ cells/well for B16/F10 cells; $3 \times 10^{5}$ cells/well for MDA-MB-435 cells). The cells were incubated in serum-reduced medium for $6 \mathrm{~h}$ and wounded in a line across the well with a 200- $\mu$ l pipette tip, which was followed by washing twice with serum-reduced medium. The cells were incubated with different concentrations of gintonin for 20-24 h. The image of the wounded area was captured and the recovery of the area was analyzed with an inverted fluorescence microscope (AxioVert200; Carl Zeiss AG, Oberkochen, Germany) at x100 magnification.

Boyden chamber assay. The chemotactic motility of the cells through the membrane was measured using a modified Boyden chamber (Neuro Probe Inc., Gaithersburg, MD, USA) (23). A polycarbonate membrane with $8-\mu$ m pores was coated with fibronectin. Either gintonin, Brp-LPA or LPA $\mathrm{C}_{18: 2}$ in DMEM (0.1\% BSA and $0.2 \% \mathrm{FBS}$ ) was added to the lower chambers. The Boyden chamber was assembled by first laying down the membrane coated with fibronectin and subsequently, the top chamber on the lower chambers. Cells $\left(5 \times 10^{4}\right.$ cells/well) were added to the top chambers and incubated for the indicated time-periods at $37^{\circ} \mathrm{C}$. The cells on the membrane were fixed and stained with Diff-Quik (Sysmex Corporation, Kobe, Japan) and mounted on slide glass. Non-migrated cells were removed with Kimwipes. The migrated cells in 4 fields were counted under a microscope (light microscopy) at x200 magnification. The images were photographed with a dark-field microscope (Eclipse 80i; Nikon Corporation, Tokyo, Japan).

Cell proliferation assay. Cell proliferation was determined using a BrdU incorporation assay, which measures DNA synthesis (16) and a XTT-based assay, which measures cell viability based on the activity of mitochondrial enzymes (24). Briefly, the cells were seeded at $3 \times 10^{3}$ cells per well in 96-well plates and incubated for $24 \mathrm{~h}$. The cells were then washed with DMEM and incubated for $6 \mathrm{~h}$ with DMEM containing $0.2 \%$ FBS. The cells were washed with fresh DMEM (0.2\% FBS) again and incubated with either gintonin or Brp-LPA at the indicated concentrations. After $48 \mathrm{~h}$, cell proliferation was assessed by a BrdU ELISA assay (16) and XTT assay as previously described (24). 
Evaluation of in vivo antitumor activity. Male C57BL/6 mice (Koatech Technology Corporation, Seoul, Korea) 6 weeks of age were housed under specific pathogen-free conditions. In the metastatic model, B16/F10 melanoma cells ( $1 \times 10^{5}$ cells/ $0.1 \mathrm{ml}$ PBS per mouse) were injected into the tail vein. Mice were orally administered saline solution (control), gintonin (50 or $100 \mathrm{mg} / \mathrm{kg}, 1$ or $2 \mathrm{mg} / 0.1 \mathrm{ml}$ saline per dose) or $\mathrm{LPA} \mathrm{C}_{18: 2}(2 \mathrm{mg} / \mathrm{kg}$ in $0.1 \% \mathrm{BSA})$ daily for 3 weeks, commencing 3 days before or 1,4 or 7 days after the cell injection. Two or three weeks after the cell injection, the mice were anesthetized with Zoletil 50 and Rompun, sacrificed, and the lungs were excised. The number of nodules was counted. In the subcutaneous model, tumors were produced by injecting B16/F10 melanoma cells ( $5 \times 10^{4}$ cells/0.2 ml PBS per mouse) into the left flank of each mouse ( $n=5$ per group). Mice were orally administered saline solution (control) or gintonin $(100 \mathrm{mg} / \mathrm{kg}, 0.1 \mathrm{ml}$ each dose) daily for 3 weeks, commencing 3 days before and continuing after the cell injection. Tumor growth was recorded with a caliper and calculated as $\mathrm{V}=0.52 \mathrm{x} \mathrm{d}^{2} \times \mathrm{D}(\mathrm{D}$, long diameter; $\mathrm{d}$, short diameter). Body weight was also determined 3 times a week. After 3 weeks of treatment, the mice were sacrificed and the tumors were excised and examined histologically.

Histology and histochemistry. Tumor tissues were fixed with $4 \%$ formaldehyde and embedded in paraffin. The paraffin tissue sections were fixed and stained with hematoxylin and eosin in order to examine tumor progression. In order to observe the microvessels of the tumor tissues, tissue sections were fixed and stained with a von Willebrand factor (vWF) antibody according to the staining protocol for immunohistochemistry. The vessels were observed under a microscope (x200 magnification) and the number in each field $\left(0.322 \mathrm{~mm}^{2}\right)$ was counted. Ten fields were randomly chosen for each group.

Ethics. Animal experiments were conducted in strict accordance with the recommendations in the Guide for the Care and Use of Laboratory Animals of the National Institutes of Health. The experimental protocol was approved by the Institutional Animal Care and Use Committee of Konkuk University, Seoul, Korea (no. KU08095).

Statistical analysis. The data are expressed as the means \pm standard error of the mean (SEM). Statistical comparisons between the controls and the treated experimental groups were performed using Student's t-tests. A value of $\mathrm{p}<0.05$ was considered to indicate a statistically significant difference.

\section{Results}

Gintonin effects on ATX activity. The inhibitory effects of gintonin on ATX activity were determined using an ATX assay kit with the fluorogenic substrate, FS-3, at the range of 0.1 to $10 \mu \mathrm{g} / \mathrm{ml}$ (Fig. 1A) (18). Gintonin $(10 \mu \mathrm{g} / \mathrm{ml})$ potently inhibited ATX activity in a concentration-dependent manner. The $\mathrm{IC}_{50}$ was $0.35 \pm 0.09 \mu \mathrm{g} / \mathrm{ml}$. As a positive ATX activity inhibitor, Brp-LPA also inhibited ATX activity at concentrations of 30 to 2,430 nM (Fig. 1B). The $\mathrm{IC}_{50}$ was $492.5 \pm 118.7 \mathrm{nM}$, which was consistent with that presented in previous reports (Fig. 1B) (10). These results demonstrate that gintonin is effective as an ATX inhibitor, similar to Brp-LPA.
Gintonin inhibits the ATX secretory activity of melanoma cells. The ATX secretory activity was determined using the concentrated medium obtained from the melanoma cells in the absence or presence of gintonin. Gintonin significantly inhibited the ATX secretory activity of mouse B16/F10 and human MDA-MB-435 cells (Fig. 1C and D). Gintonin $(10 \mu \mathrm{g} / \mathrm{ml})$ inhibited the ATX secretory activity of the B16/F10 and MDA-MB-435 cells by $50.1 \pm 4.7$ and $81.8 \pm 1.9 \%$, respectively. As a positive control, we also used LPA $\mathrm{C}_{18: 2}$. LPA $\mathrm{C}_{18: 2}$ also inhibited ATX secretory activity in a concentration-dependent manner (Fig. 1E). These results indicate that gintonin inhibits the ATX secretory activity of melanoma cells.

Gintonin inhibits melanoma cell migration. Since the secretion of ATX stimulates cell migration and gintonin inhibits ATX secretory activity, we examined whether the gintonin-induced inhibition of ATX activity could be coupled with the cell migration inhibition. The gintonin effects on melanoma cell migration were determined by a scratch-wound healing assay (Fig. 2) and the modified Boyden chamber assay (Fig. 3). In the scratch-wound healing assay, gintonin dose-dependently reduced the migration and motility of the B16/F10 cells (Fig. 2A). Gintonin $(30 \mu \mathrm{g} / \mathrm{ml})$ reduced the migration of B16/F10 cells by $73.5 \pm 6.1 \%$. Similarly, gintonin inhibited MDA-MB-435 cell migrations by $40-60 \%$ at concentrations of $30-100 \mu \mathrm{g} / \mathrm{ml}$ (Fig. 2B). The $\mathrm{IC}_{50}$ values for cell migration were $14.9 \pm 17.2$ and $69.4 \pm 31.2 \mu \mathrm{g} / \mathrm{ml}$ in the mouse and human melanoma cells, respectively. Brp-LPA $(10 \mu \mathrm{M})$, which was the positive control, inhibited the migration of B16/F10 and MDA-MB-435 cells by $46.2 \pm 11.7$ or $62.6 \pm 4.2 \%$, respectively.

In a modified Boyden chamber assay, gintonin also reduced the chemotactic motility (transmigration) of B16/F10 and MDA-MB-435 cells in a dose-dependent manner (Fig. 3A and B). Gintonin at 10 and $30 \mu \mathrm{g} / \mathrm{ml}$ induced approximately $90 \%$ inhibition of migration in both cells. The $\mathrm{IC}_{50}$ values for migration were $0.96 \pm 0.08$ and $4.82 \pm 1.48 \mu \mathrm{g} / \mathrm{ml}$ in the mouse and human melanoma cells, respectively. Brp-LPA $(10 \mu \mathrm{M})$ and LPA $\mathrm{C}_{18: 2}(10 \mu \mathrm{M})$, which were the positive controls, inhibited the migration of $\mathrm{B} 16 / \mathrm{F} 10$ cells by $79.6 \pm 4.2$ and $96.7 \pm 0.6 \%$, respectively. Similarly, Brp-LPA $(10 \mu \mathrm{M})$ and LPA C $_{18: 2}(10 \mu \mathrm{M})$ inhibited the migration of MDA-MB- 435 cells by $80.8 \pm 4.0$ and $63.1 \pm 9.0 \%$, respectively. These results demonstrate that gintonin exerts inhibitory effects on cancer cell migration.

Gintonin effects on melanoma cell growth. To determine whether the gintonin-induced inhibition of cancer cell migration was due to cell growth inhibition, the gintonin effects on cell growth were examined by BrdU incorporation (25) and XTT-based assays (26) (Fig. 4). Gintonin slightly reduced cell proliferation at $10 \mu \mathrm{g} / \mathrm{ml}$, which is a concentration that exerts a strong inhibitory effect on cancer cell migration (Figs. 2 and 3). However, gintonin at concentrations $>50 \mu \mathrm{g} / \mathrm{ml}$ inhibited BrdU incorporation and mitochondrial respiratory enzyme activity by $80-90 \%$ in B16/F10 (Fig. 4A and B) and MDA-MB-435 cells (Fig. 4C and D). Brp-LPA at $10 \mu \mathrm{M}$ inhibited $<20 \%$ of the proliferation of B16/F10 (Fig. 4A and B) and MDA-MB-435 cells (Fig. 4C and D). These results demonstrate that gintonin does not affect cell growth at concentrations that inhibit migration and that the gintonin-induced inhibition of cancer cell migration does not occur through cell growth inhibition. 


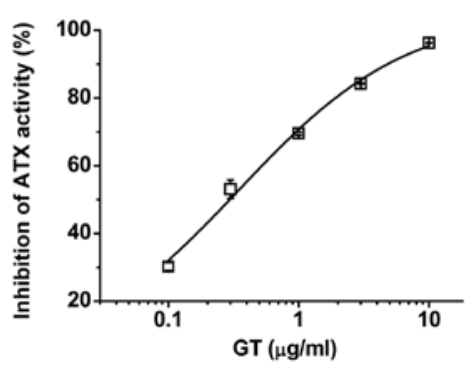

C

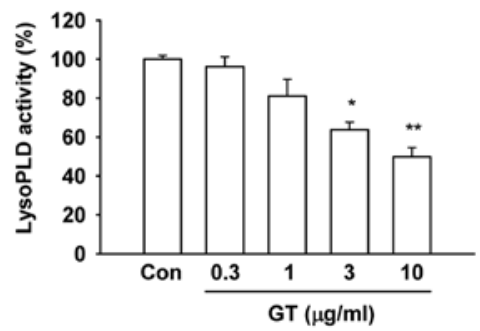

E

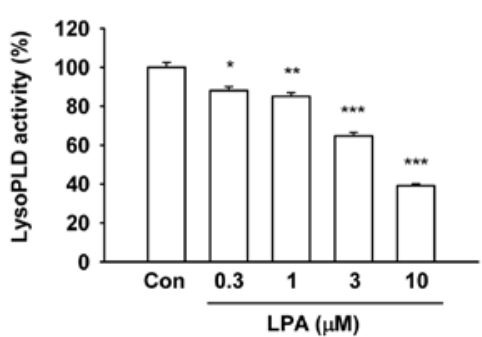

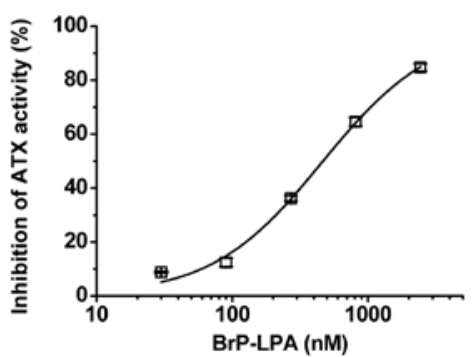

D

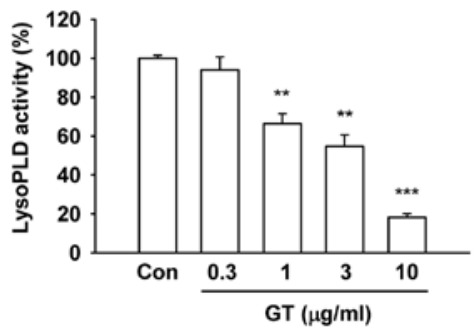

Figure 1. Gintonin inhibits autotaxin (ATX) activity. (A and B) An ATX inhibitor test was performed using the screening test kit as described in Materials and methods. ATX was incubated with either (A) gintonin (GT) or (B) Brp-LPA at different concentrations in a 96-well plate, which was followed by the addition of FS-3. The resulting fluorescence was measured for $30 \mathrm{~min}$ and the relative inhibition of ATX activity was calculated. The gintonin or LPA $C_{18: 2}$ effects on the lysophospholipase D (Lyso-PLD) activity of ATX that was obtained from the conditioned medium is shown in (C) B16/F10 cells and (D and E) MDA-MB-435 cells. The resulting fluorescence was measured over time. The relative LysoPLD activity was quantified compared to the untreated control cells (Con). The data are presented as the means $\pm \operatorname{SEM}(\mathrm{n}=6) .{ }^{*} \mathrm{p}<0.05,{ }^{* *} \mathrm{p}<0.01$ and ${ }^{* * *} \mathrm{p}<0.001$, compared to the untreated controls.

A
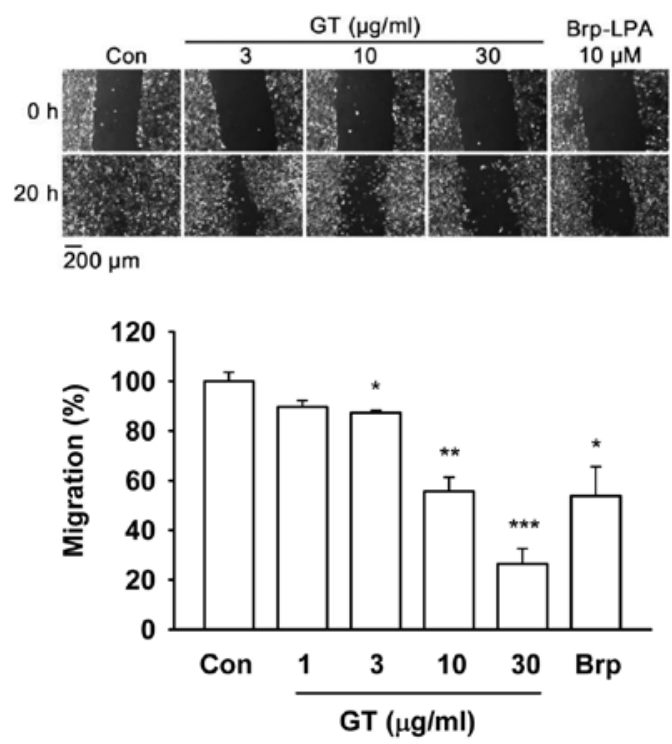

B
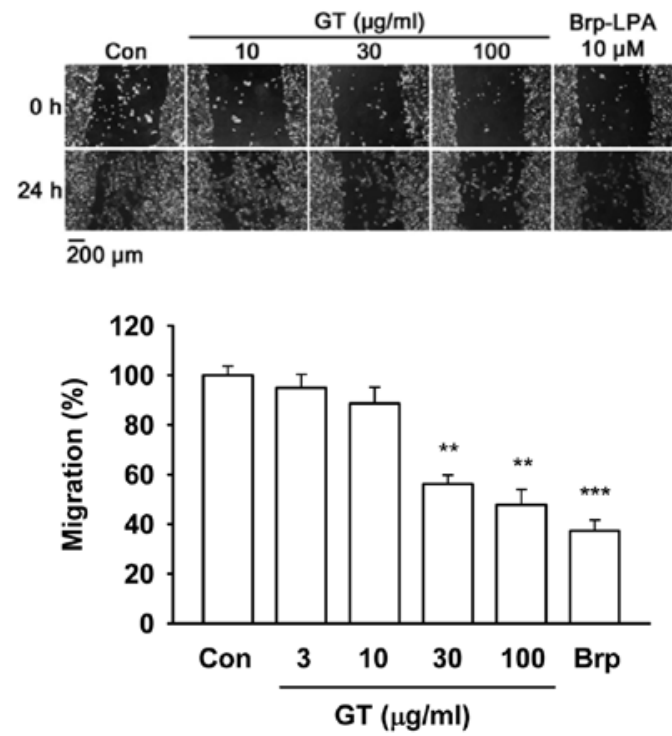

Figure 2. Gintonin inhibits the migration of (A) B16/F10 and (B) MDA-MB-435 cells. Confluent cells were scratched and incubated with either gintonin (GT) at the indicated concentrations or Brp-LPA $(10 \mu \mathrm{M})$ in DMEM containing 0.2\% FBS (B16/F10 cells) or 5\% FBS (MDA-MB-435 cells) for 20-24 h. The relative migration was quantified compared to the untreated control cells (Con). The data are presented as the means $\pm \operatorname{SEM}(\mathrm{n}=3-6) .{ }^{*} \mathrm{p}<0.05,{ }^{* * *} \mathrm{p}<0.01$ and ${ }^{* * * *} \mathrm{p}<0.001$, compared to the untreated controls. 
A
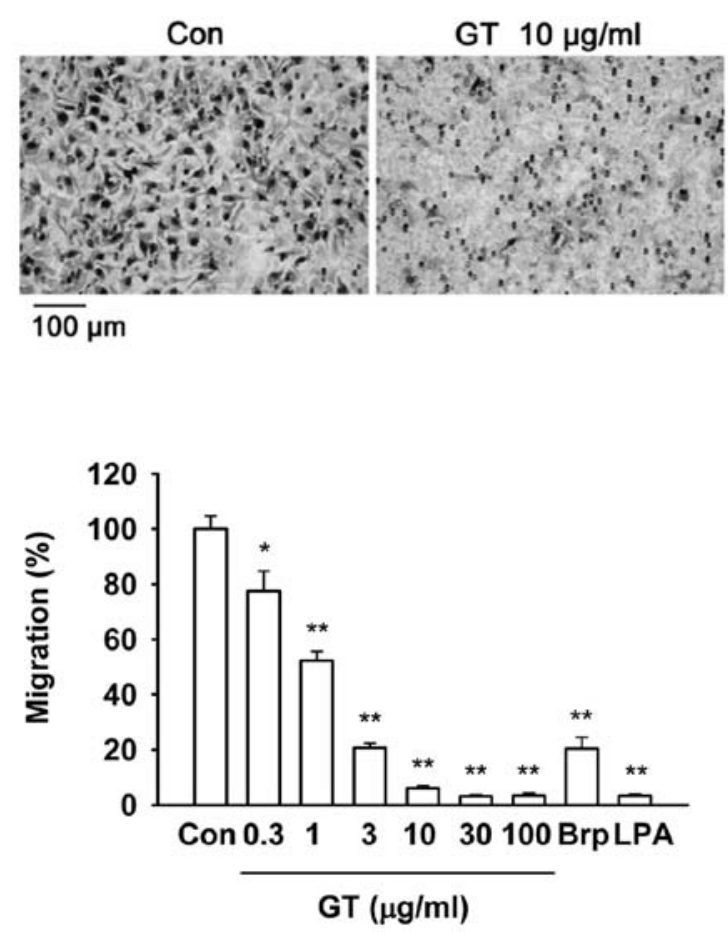

B
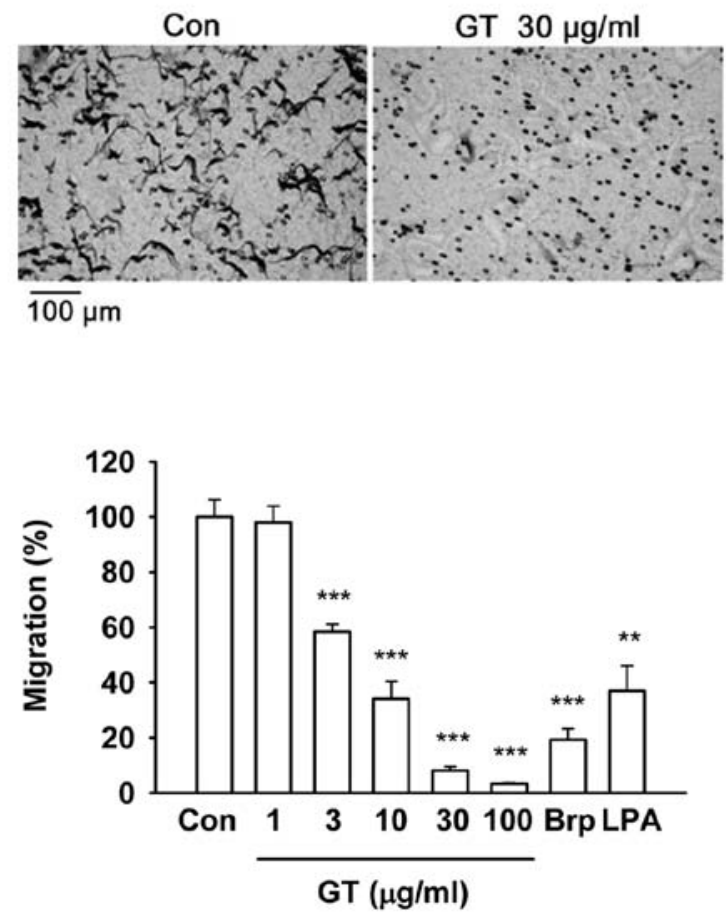

Figure 3. Gintonin inhibits the transmigration of (A) B16/F10 and (B) MDA-MB-435 cells. Either gintonin (GT) at the indicated concentrations, Brp-LPA (10 $\mu$ M), or LPA C18:2 $(10 \mu \mathrm{M})$ in DMEM containing $0.2 \%$ FBS and 0.1\% bovine serum albumin (BSA) was loaded into the lower wells of the modified Boyden chamber that was sectioned by a fibronectin-coated polycarbonate membrane with $8-\mu \mathrm{m}$ pores. The cells were trypsinized and loaded into the upper wells of the chamber and incubated for (A) $3 \mathrm{~h}$ or (B) $7 \mathrm{~h}$ for the migration test, as described in Materials and methods. The stained migrated cells in each field were observed and counted at x200 magnification. The relative migration of the treated cells was quantified compared to the untreated control cells (Con). The data are presented as the means $\pm \operatorname{SEM}(\mathrm{n}=16) .{ }^{*} \mathrm{p}<0.05,{ }^{* *} \mathrm{p}<0.05$ and $^{* * * *} \mathrm{p}<0.05$, compared to the untreated controls.

A

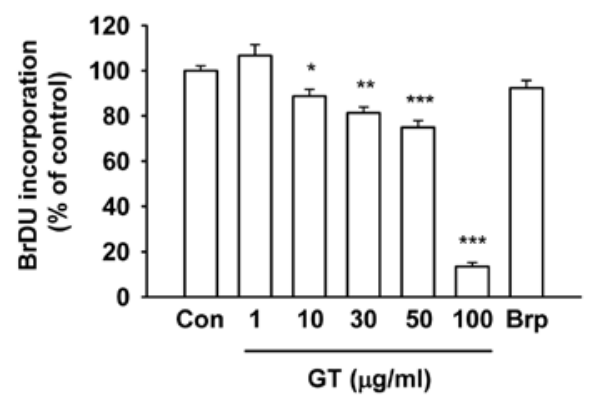

C

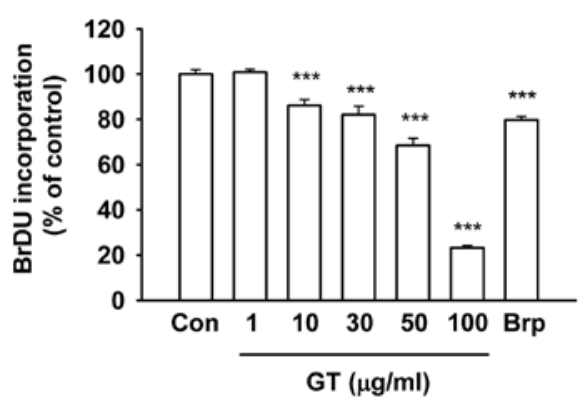

B

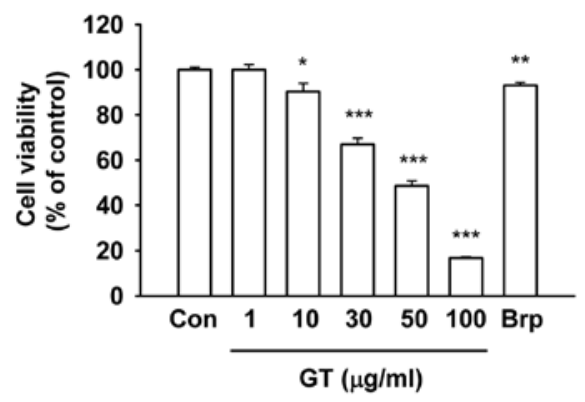

D

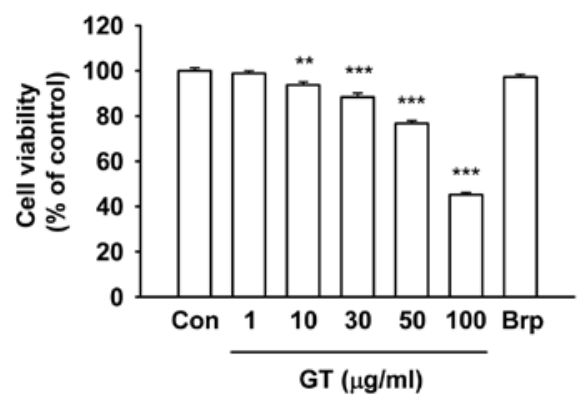

Figure 4. Effects of gintonin on the proliferation of (A and B) B16/F10 and (C and D) MDA-MB-435 cells. Cells were treated with the indicated concentrations of gintonin (GT) or Brp-LPA $(10 \mu \mathrm{M})$ and subjected to (A and C) a BrdU incorporation assay and (B and D) a XTT assay, as described in Materials and methods. The data are presented as the means \pm SEM. $(n=6) .{ }^{*} p<0.05,{ }^{* *} p<0.01$ and ${ }^{* * *} \mathrm{p}<0.001$, compared to the untreated controls. 

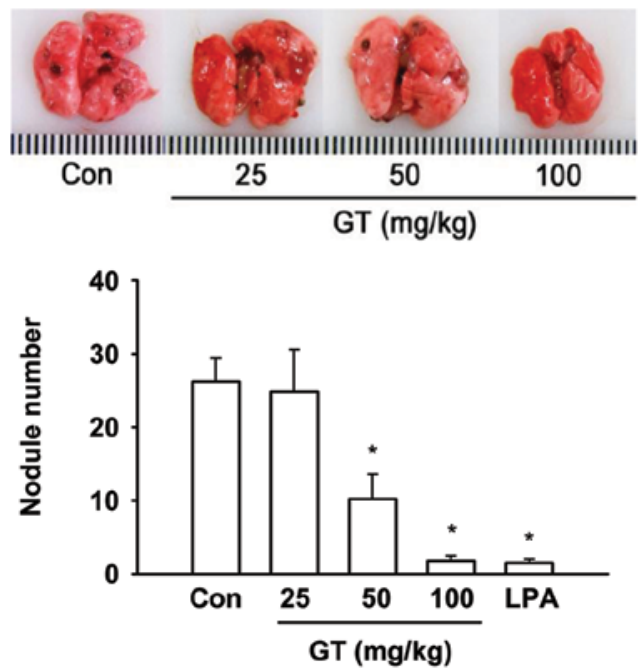

C

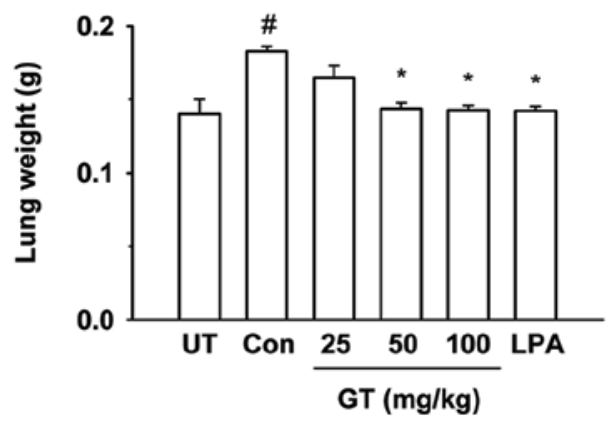

B
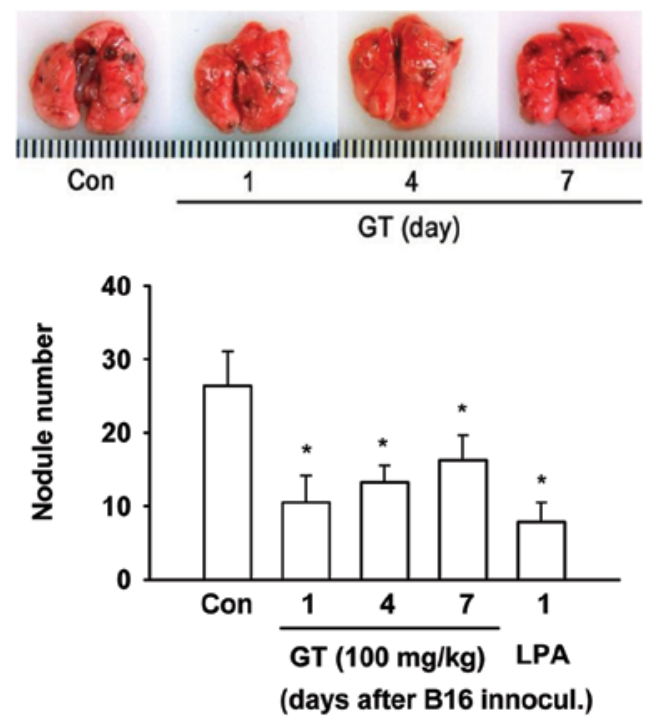

D

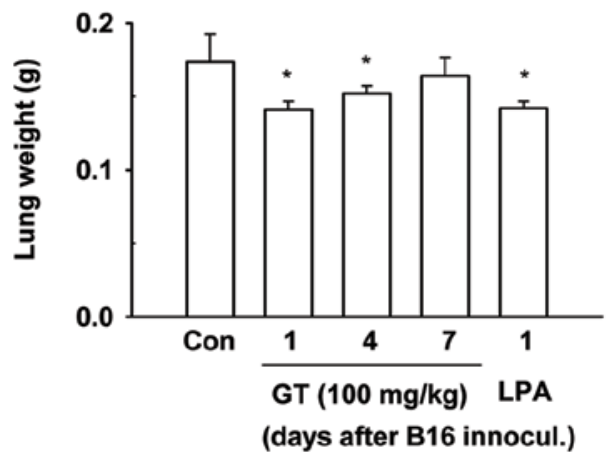

Figure 5. Gintonin reduces B16/F10 lung metastases in mice. (A and C) Gintonin (GT) or LPA C18:2 were orally administered to mice for 3 weeks, commencing 3 days prior to B16/F10 melanoma cell inoculation at the indicated doses or $2 \mathrm{mg} / \mathrm{kg}$ for LPA C 18:2. $_{\text {. }}$ (B and D) Gintonin (100 mg/kg, daily) or LPA C18:2 (2 mg/kg, daily) was orally administered to the mice for 3 weeks, commencing at the indicated days after B16/F10 cells innoculation. Nodule numbers (A and B) showed that gintonin treatment significantly reduced lung metastasis in a dose- and time-dependent manner. The data are presented as the means \pm SEM $(n=5)$. ${ }^{*}<<0.05$, compared with the control group injected with B16/F10 cells; ${ }^{\# p}<0.05$, compared with the untreated normal mice. Scale on images $=1 \mathrm{~mm}$.

Gintonin inhibits lung metastasis of melanoma cells in mice. Since the above results showed the possibility that gintonin may affect metastasis in vivo through the inhibition of ATX activity and cell migration, we examined the antimetastatic effects of gintonin. For this purpose, we used B16/F10 mouse melanoma cells for the in vivo lung metastasis experiments $(19,27)$. We examined the gintonin effects on lung metastasis after the intravenous administration of B16/F10 mouse melanoma cells. Gintonin treatment at a daily oral dose of 25,50 and $100 \mathrm{mg} / \mathrm{kg}$ for 3 weeks commencing 3 days before B16/F10 inoculation resulted in $24.8 \pm 5.8,10.2 \pm 3.4$ and $1.8 \pm 0.7$ nodules, respectively, compared to $26.2 \pm 3.2$ nodules in the saline control group (Fig. 5A). Thus, gintonin suppressed the lung metastasis of melanoma cells in a dose-dependent manner. The weights of the lungs also correlated with metastasis (Fig. 5C). LPA $C_{18: 2}(2 \mathrm{mg} / \mathrm{kg})$, which was used as the positive control, with treatment commencing 3 days before B16/F10 inoculation, also inhibited lung metastasis. We then examined the effects of the gintonin post-treatment in lung metastasis. To determine at which time-point gintonin inhibits metastasis, a 2-week treatment of gintonin [daily dose, $100 \mathrm{mg} / \mathrm{kg}$, per os (p.o.)] was initiated after 1, 4, or 7 days after B16/F10 inoculation into the tail veins of the mice (Fig. 5B). As shown in Fig. 5, the early administration of gintonin or LPA $\mathrm{C}_{18: 2}$ after B16/F10 cell inoculation was more effective for the inhibition of lung metastasis of melanoma cells. These results indicated that the pre-treatment with gintonin and LPA $\mathrm{C}_{18: 2}$ prior to $\mathrm{B} 16 / \mathrm{F} 10$ cell inoculation was more effective in inhibiting lung metastasis than gintonin post-treatment.

Gintonin inhibits tumor growth in mice. We then examined the gintonin effects on tumor growth. B16/F10 cells were injected subcutaneously into the left flanks of mice. Tumor volume exponentially increased in the saline-treated control mice after the cell injections, reaching approximately $3,000 \mathrm{~mm}^{3} 3$ weeks after the cell injection (Fig. 6A and C). The oral administration of gintonin $(100 \mathrm{mg} / \mathrm{kg}$, p.o.) markedly suppressed tumor growth, showing limited tumor volumes that were $<1,000 \mathrm{~mm}^{3}$ 3 weeks after the cell injection (Fig. 6A and C). Increased tumor volume tended to correlate with increased body weight 
A

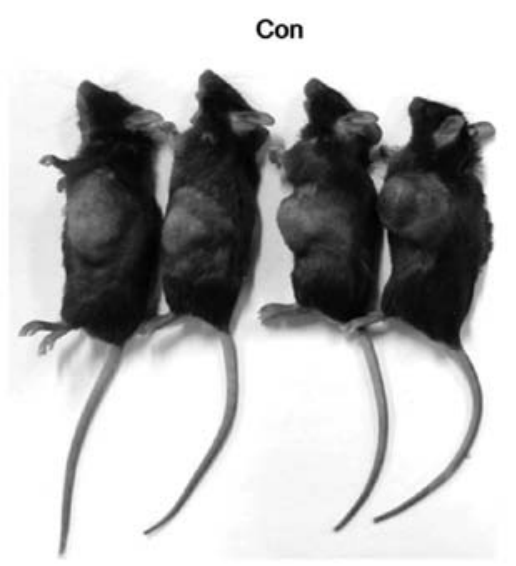

B

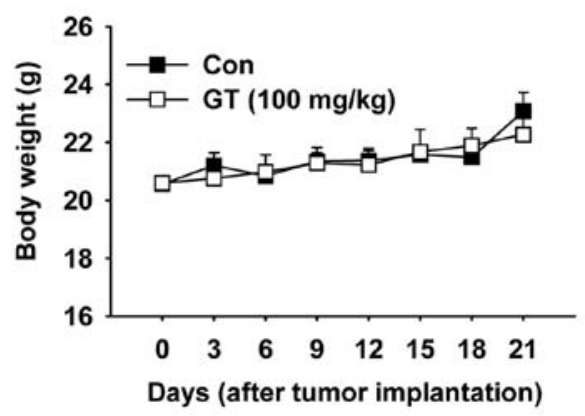

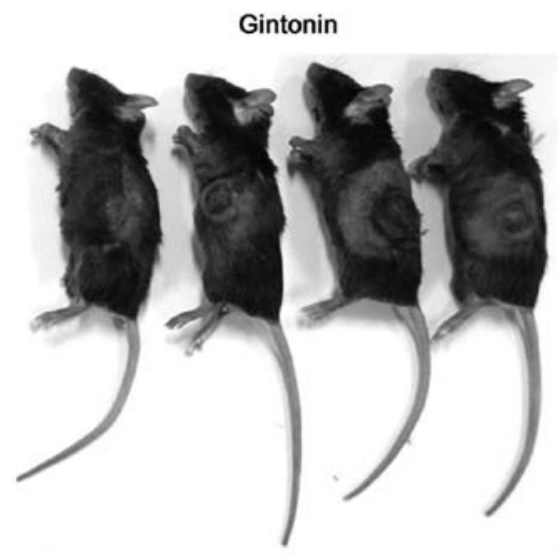

C

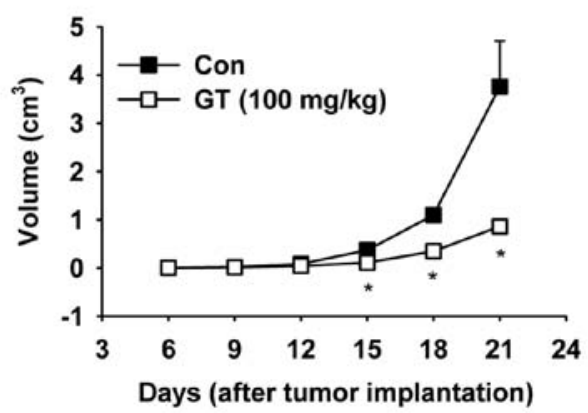

Figure 6. Gintonin decreases tumor size and vessel numbers in mice. Saline (control) or gintonin (GT) (100 mg/kg, daily) were orally administered to the mice for 3 weeks, commencing 3 days prior to the subcutaneous injection of B16/F10 cells, as described in Materials and methods. (A) Images of tumor-bearing mice. (B) Body weights of mice. (C) Tumor volume. The data are presented as the means \pm SEM ( $\mathrm{n}=5)$. ${ }^{*} \mathrm{p}<0.05$, compared to the controls.

without significant difference in body weights between the groups (Fig. 6B). Hematoxylin and eosin staining of the tumor tissues revealed that the tumor tissues from the control group were more vulnerable to necrosis compared to those from the gintonin-treated group (Fig. 7). Moreover, the tumor tissues in the mice treated with gintonin showed less mitosis and pleiomorphisms compared to those from the control group (Fig. 7). In addition, immunohistochemical analyses were performed using the tumor tissues with antibodies for vWF in order to determine the development of vessels and the numbers of vessels in the tumor tissues. Gintonin treatment reduced vWF-stained blood vessel numbers compared to the saline control mice (Fig. 7A and B). These results demonstrate that gintonin exerts antimetastatic activities, as well as antitumor activities in vivo.

\section{Discussion}

Metastasis is the process by which a certain cancer spreads from the location at which a tumor first arises to distant locations in the body (28). Metastasis usually depends on cancer cells having 2 separate abilities, increased motility and invasion. Cancer recurrence by metastasis is one of the main causes of mortality in cancer patients and is currently a main target for cancer therapy (27).

In a previous study, we demonstrated that gintonin activates LPA receptors and exhibits LPA receptor-mediated cellular effects (16). However, since ginseng has cancer preventive effects and anticancer activities $(13,14)$ and LPA $C_{18: 2}$ acts as a strong negative regulator of ATX activity (17), we investigated whether gintonin, which is rich in LPA $\mathrm{C}_{18: 2}$, exerts in vitro and in vivo antimetastatic activities.

In the present study, we made 3 key observations that indicate that gintonin has antimetastatic and antitumor activities. First, we observed that gintonin and LPA $\mathrm{C}_{18: 2}$ potently inhibited the activity of ATX that was secreted from melanoma cells. Second, gintonin strongly blocked cell migration at low concentrations with a slight inhibition of tumor cell proliferation. Third, the oral administration of gintonin and LPA decreased the number of metastatic lung nodule formations induced by the tail-vein inoculation of melanoma cells. Gintonin also reduced the size of tumors induced by the subcutaneous inoculation of melanoma cells in mice. Thus, the results showed that the gintonin-induced inhibition of ATX activity and cell migration may be coupled with the attenuation of metastasis and tumor growth.

In previous reports, Deng et al demonstrated that orallyadministered LPA restored intestinal injuries induced by radiation exposure (29). Adachi et al also showed that orallyadministered LPA attenuated gastric ulcer formation induced by stress (30). In the present study, we further demonstrate that orally-administered gintonin, as well as LPA $\mathrm{C}_{18: 2}$ exert metastasis-related anticancer activity. We previously demonstrated that gintonin activated LPA receptor subtypes with high affinity 


\section{A}

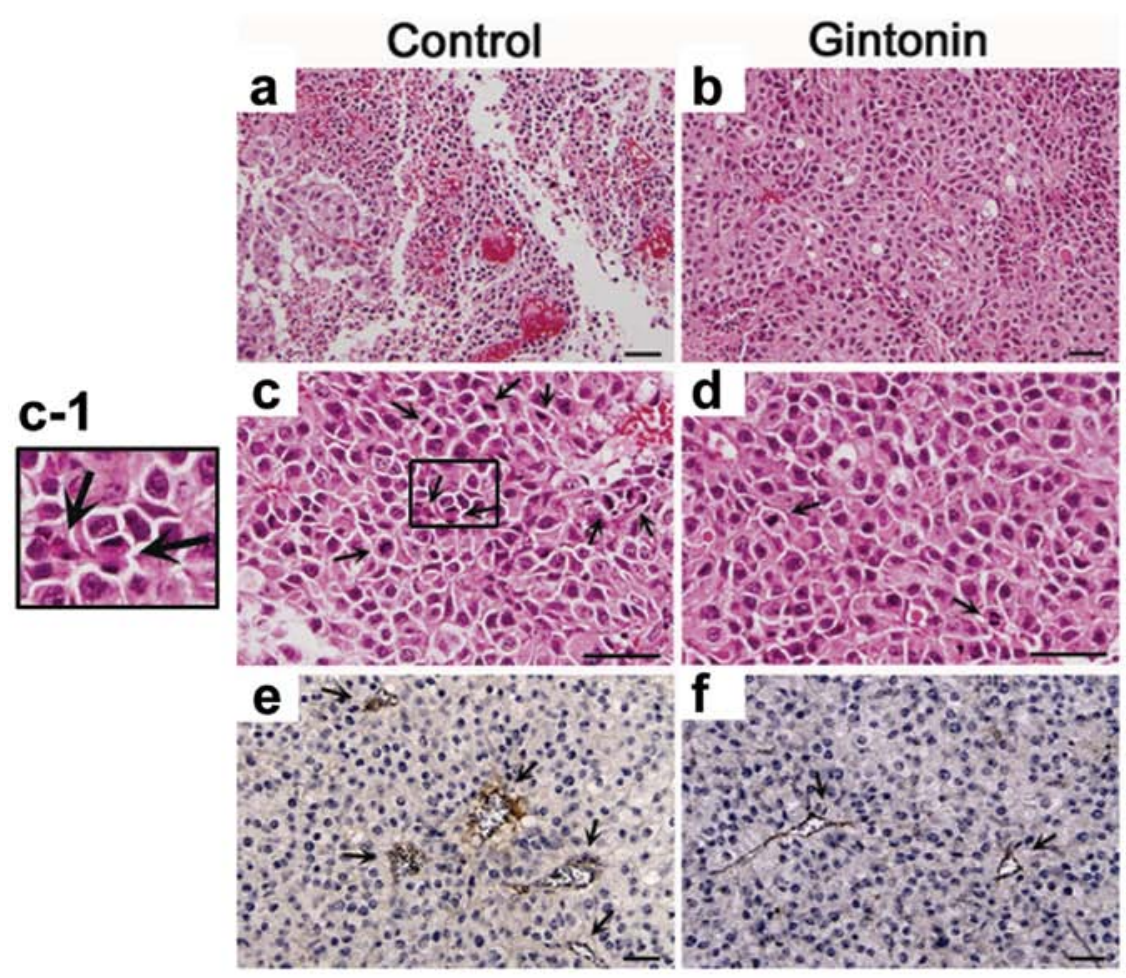

B

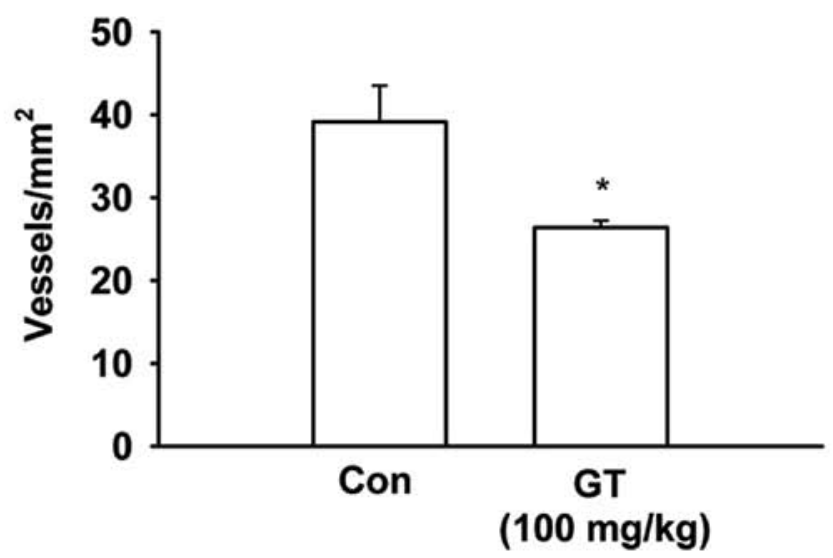

Figure 7. Histology of tumor tissues. Saline (control) or gintonin (GT) $(100 \mathrm{mg} / \mathrm{kg}$, daily) were orally administered to the mice for 3 weeks, commencing 3 days prior to the subcutaneous injection of B16/F10 cells, as described in Materials and methods. (A) Microscopic images of tumor tissues. Tumor tissues were stained with hematoxylin and eosin (a-d) or with von Willebrand factor (vWF) antibody (e and f). Cells in mitosis (c and d) and vessels (e and f) in the tissue sections are indicated by arrows. Panel c-1, close-up of the square in (c). Gintonin treatment significantly decreased (b) necrosis, (d) mitosis and pleiomorphisms and (f) vascularity, compared to the saline control group. (B) Numbers of vessels in tumor tissues. The data are presented as the means $\pm S E M(n=5)$. ${ }^{*} p<0.05$, compared to the controls. Scale on images, $35 \mu \mathrm{m}$.

and increased the migration and proliferation of human umbilical vein endothelial cells and induced morphological changes in neuronal cells via LPA receptors (16). In the present study, gintonin inhibited the migration of melanoma cells in vitro. Thus, gintonin and LPA may have differential effects that are cell type-dependent or may have dual actions. One action is as an ATX inhibitor and the other is as a LPA receptor ligand. It is likely that, in pathophysiological conditions such as cancer, gintonin-induced antimetastatic and antitumor activities are achieved through the inhibition of ATX activity. A line of evidence supports this notion. Gintonin as well as LPA $\mathrm{C}_{18: 2}$ inhibited the in vitro activities of purified ATX and secreted ATX in cancer cell medium (Fig. 1). A number of studies have shown that the inhibition of ATX activity results in a decrease in LPA production and antimetastasis in different types of tumor (10-12,31-34). Thus, we speculated that gintonin may 
negatively affect ATX activity, resulting in an attenuation of endogenous LPA production.

Of note, we observed that the inhibition of metastasis of melanoma cells by gintonin was much more effective when mice were orally pre-treated with gintonin prior to melanoma cell inoculation (Fig. 5). Thus, the oral gintonin pre-treatment may be also coupled with the preventive effects against metastasis. In addition, although pre-treatment with gintonin (100 mg/kg, p.o.) did not suppress tumor formation in the mice subcutaneously injected with melanoma cells as much as it did lung metastasis, it also significantly reduced tumor size and angiogenesis compared to the saline control group. Taken together, these results suggest that gintonin inhibits ATX activity to suppress the subsequent ATX-mediated metastasis and tumor growth. Currently, we are investigating how gintonin binds to or interacts with ATX for the inhibition of ATX activity.

In conclusion, the results from the present study demonstrate that the gintonin-induced inhibition of ATX activity may be the molecular basis of the gintonin-induced antimetastatic and antitumor activities. Finally, we propose that gintonin may be a useful agent for the prevention of metastasis, particularly when used in combination with cancer-related anti-proliferative drugs.

\section{Acknowledgements}

The present study was supported by grants from the Basic Science Research Program (2011-0021144) and the Priority Research Centers Program through the National Research Foundation of Korea (NRF), which is funded by the Ministry of Education, Science and Technology (2012-0006686) and BK21 to S.-Y. Nah.

\section{References}

1. Moolenaar WH: LPA: a novel lipid mediator with diverse biological actions. Trends Cell Biol 4: 213-219, 1994.

2. Mills GB and Moolenaar WH: The emerging role of lysophosphatidic acid in cancer. Nat Rev Cancer 3: 582-591, 2003.

3. Chun J, Hla T, Lynch KR, Spiegel S and Moolenaar WH: International Union of Basic and Clinical Pharmacology. LXXVIII. Lysophospholipid receptor nomenclature. Pharmacol Rev 62: 579-587, 2010.

4. Kranenburg O and Moolenaar WH: Ras-MAP kinase signaling by lysophosphatidic acid and other $\mathrm{G}$ protein-coupled receptor agonists. Oncogene 20: 1540-1546, 2001.

5. Tokumura A, Majima E, Kariya Y, Tominaga K, Kogure K, Yasuda K and Fukuzawa K: Identification of human plasma lysophospholipase D, a lysophosphatidic acid-producing enzyme, as autotaxin, a multifunctional phosphodiesterase. J Biol Chem 277: 39436-39442, 2002.

6. Umezu-Goto M, Kishi Y, Taira A, Hama K, Dohmae N, Takio K, Yamori T, Mills GB, Inoue K, Aoki J and Arai H: Autotaxin has lysophospholipase D activity leading to tumor cell growth and motility by lysophosphatidic acid production. J Cell Biol 158: 227-233, 2002

7. Houben AJ and Moolenaar WH: Autotaxin and LPA receptor signaling in cancer. Cancer Metastasis Rev 30: 557-565, 2011.

8. Stracke ML, Krutzsch HC, Unsworth EJ, Arestad A, Cioce V, Schiffmann E and Liotta LA: Identification, purification and partial sequence analysis of autotaxin, a novel motility-stimulating protein. J Biol Chem 267: 2524-2529, 1992.

9. van Meeteren LA, Ruurs P, Christodoulou E, Goding JW, Takakusa H, Kikuchi K, Perrakis A, Nagano T and Moolenaar WH: Inhibition of autotaxin by lysophosphatidic acid and sphingosine 1-phosphate. J Biol Chem 280: 21155-21161, 2005 .
10. Zhang H, Xu X, Gajewiak J, Tsukahara R, Fujiwara Y, Liu J, Fells JI, Perygin D, Parrill AL, Tigyi G and Prestwich GD: Dual activity lysophosphatidic acid receptor pan-antagonist/ autotaxin inhibitor reduces breast cancer cell migration in vitro and causes tumor regression in vivo. Cancer Res 69: 5441-5449, 2009.

11. Uchiyama A, Mukai M, Fujiwara Y, Kobayashi S, Kawai N, Murofushi H, Inoue M, Enoki S, Tanaka Y, Niki T, Kobayashi T, Tigyi G and Murakami-Murofushi K: Inhibition of transcellular tumor cell migration and metastasis by novel carba-derivatives of cyclic phosphatidic acid. Biochim Biophys Acta 1771: 103-112, 2007.

12. Gupte R, Siddam A, Lu Y, Li W, Fujiwara Y, Panupinthu N, Pham TC, Baker DL, Parrill AL, Gotoh M, MurakamiMurofushi K, Kobayashi S, Mills GB, Tigyi G and Miller DD: Synthesis and pharmacological evaluation of the stereoisomers of 3-carba cyclic-phosphatidic acid. Bioorg Med Chem Lett 20: 7525-7528, 2010

13. Mochizuki M, Yoo YC, Matsuzawa K, Sato K, Saiki I, Tono-oka S, Samukawa K and Azuma I: Inhibitory effect of tumor metastasis in mice by saponins, ginsenoside-Rb2, 20(R)and 20(S)-ginsenoside-Rg3, of red ginseng. Biol Pharm Bull 18: 1197-1202, 1995.

14. Pan XY, Guo H, Han J, Hao F, An Y, Xu Y, Xiaokaiti Y, Pan Y and $\mathrm{Li}$ XJ: Ginsenoside Rg3 attenuates cell migration via inhibition of aquaporin 1 expression in PC-3M prostate cancer cells. Eur J Pharmacol 683: 27-34, 2012.

15. Pyo MK, Choi SH, Hwang SH, Shin TJ, Lee BH, Lee SM, Lim YH, Kim DH and Nah SY: Novel glycolipoproteins from ginseng. J Ginseng Res 35: 92-103, 2011.

16. Hwang SH, Shin TJ, Choi SH, Cho HJ, Lee BH, Pyo MK, Lee JH, Kang J, Kim HJ, Park CW, Shin HC and Nah SY: Gintonin, newly identified compounds from ginseng, is novel lysophosphatidic acids-protein complexes and activates $\mathrm{G}$ protein-coupled lysophosphatidic acid receptors with high affinity. Mol Cells 33: 151-162, 2012.

17. Liu XW, Sok DE, Yook HS, Sohn CB, Chung YJ and Kim MR: Inhibition of lysophospholipase D activity by unsaturated lysophosphatidic acids or seed extracts containing 1-linoleoyl and 1-oleoyl lysophosphatidic acid. J Agric Food Chem 55: 8717-8722, 2007.

18. Ferguson CG, Bigman CS, Richardson RD, van Meeteren LA, Moolenaar WH and Prestwich GD: Fluorogenic phospholipid substrate to detect lysophospholipase D/autotaxin activity. Org Lett 8: 2023-2026, 2006.

19. Poste G, Doll J, Brown AE, Tzeng J and Zeidman I: Comparison of the metastatic properties of B16 melanoma clones isolated from cultured cell lines, subcutaneous tumors and individual lung metastases. Cancer Res 42: 2770-2778, 1982.

20. Gaetano CG, Samadi N, Tomsig JL, Macdonald TL, Lynch KR and Brindley DN: Inhibition of autotaxin production or activity blocks lysophosphatidylcholine-induced migration of human breast cancer and melanoma cells. Mol Carcinog 48: 801-809, 2009.

21. Clair T, Lee HY, Liotta LA and Stracke ML: Autotaxin is an exoenzyme possessing 5'-nucleotide phosphodiesterase/ATP pyrophosphatase and ATPase activities. J Biol Chem 272: 996-1001, 1997.

22. Nam SW, Clair T, Kim YS, McMarlin A, Schiffmann E, Liotta LA and Stracke ML: Autotaxin (NPP-2), a metastasisenhancing motogen, is an angiogenic factor. Cancer Res 61: 6938-6944, 2001.

23. Moore LD, Isayeva T, Siegal GP and Ponnazhagan S: Silencing of transforming growth factor-beta1 in situ by RNA interference for breast cancer: implications for proliferation and migration in vitro and metastasis in vivo. Clin Cancer Res 14: 4961-4970, 2008.

24. Hwang SH, Rait A, Pirollo KF, Zhou Q, Yenugonda VM, Chinigo GM, Brown ML and Chang EH: Tumor-targeting nanodelivery enhances the anticancer activity of a novel quinazolinone analogue. Mol Cancer Ther 7: 559-568, 2008.

25. Porstmann T, Ternynck T and Avrameas S: Quantitation of 5-bromo-2-deoxyuridine incorporation into DNA: an enzyme immunoassay for the assessment of the lymphoid cell proliferative response. J Immunol Methods 82: 169-179, 1985.

26. Scudiero DA, Shoemaker RH, Paull KD, Monks A, Tierney S, Nofziger TH, Currens MJ, Seniff D and Boyd MR: Evaluation of a soluble tetrazolium/formazan assay for cell growth and drug sensitivity in culture using human and other tumor cell lines. Cancer Res 48: 4827-4833, 1988. 
27. Scutti JA, Matsuo AL, Pereira FV, Massaoka MH, Figueiredo CR, Moreira DF, Belizário JE and Travassos LR: Role of SOCS-1 gene on melanoma cell growth and tumor development. Transl Oncol 4: 101-109, 2011.

28. Leberi MF and Efferth T: Molecular principles of cancer invasion and metastasis (Review). Int J Oncol 34: 881-895, 2009.

29. Deng W, Shuyu E, Tsukahara R, Valentine WJ, Durgam G, Gududuru V, Balazs L, Manickam V, Arsura M, VanMiddlesworth L, Johnson LR, Parrill AL, Miller DD and Tigyi G: The lysophosphatidic acid type 2 receptor is required for protection against radiation-induced intestinal injury. Gastroenterology 132: 1834-1851, 2007.

30. Adachi M, Horiuchi G, Ikematsu N, Tanaka T, Terao J, Satouchi K and Tokumura A: Intragastrically administered lysophosphatidic acids protect against gastric ulcer in rats under water-immersion restraint stress. Dig Dis Sci 56: 2252-2261, 2011.

31. $\mathrm{Xu} X$ and Prestwich GD: Inhibition of tumor growth and angiogenesis by a lysophosphatidic acid antagonist in an engineered three-dimensional lung cancer xenograft model. Cancer 116 : 1739-1750, 2010.
32. Gierse J, Thorarensen A, Beltey K, Bradshaw-Pierce E, CortesBurgos L, Hall T, Johnston A, Murphy M, Nemirovskiy O, Ogawa S, Pegg L, Pelc M, Prinsen M, Schnute M, Wendling J, Wene S, Weinberg R, Wittwer A, Zweifel B and Masferrer J: A novel autotaxin inhibitor reduces lysophosphatidic acid levels in plasma and the site of inflammation. J Pharmacol Exp Ther 334: 310-317, 2010.

33. Albers HM, Dong A, van Meeteren LA, Egan DA, Sunkara M, van Tilburg EW, Schuurman K, van Tellingen O, Morris AJ, Smyth SS, Moolenaar WH and Ovaa H: Boronic acid-based inhibitor of autotaxin reveals rapid turnover of LPA in the circulation. Proc Natl Acad Sci USA 107: 7257-7262, 2010.

34. van Meeteren LA, Brinkmann V, Saulnier-Blache JS, Lynch KR and Moolenaar WH: Anticancer activity of FTY720: phosphorylated FTY720 inhibits autotaxin, a metastasis-enhancing and angiogenic lysophospholipase D. Cancer Lett 266: 203-208, 2008. 